\title{
韵 Naturally occurring radioactive materials and the regulatory challenges to the zircon industry
}

\author{
by K. Harlow
}

\section{Synopsis}

Zircon is a naturally occurring radioactive material (NORM) and as such is subject to a variety of regulations around the world. The regulatory processes and their implementation are summarized and the key issues affecting zircon and zirconia highlighted. Having absorbed the activities of the former Zircon Minerals Committee, the strategy of the Zircon Industry Association (ZIA) is to be the 'go-to place' for information on these matters, and its activities in the NORM space are described. Chemical industry regulations such as REACH are spreading around the world, and the paper provides an update of their status in the key jurisdictions. As mineral sands are transported to market in oceangoing vessels, they are subject to the regulations of the International Maritime Organization, which are summarized in the paper.

\section{Keywords}

zircon, zirconia, radioactivity, safety and health, environment, regulatory issues. globally traded zircon supply. Geographically, ZIA's members are in the USA, Latin America, Europe, Africa, and Asia. South Africa accounts for a quarter of the world's production of zircon, being second only to Australia (40\%). Major dunal sand deposits are mined in the coastal regions of ZwaZuluNatal and Namakwaland. ZIA producer members are listed in Table I.

This paper describes some of the work that ZIA has commissioned over the past two years to support its members' NORM activities, as well as on the impact of Europe's REACH (Registration, Evaluation and Authorisation of Chemicals) regulations and their derivatives around the world.

\section{Zircon and radiation exposure}

Materials are classified based on the level of radioactivity they contain, and further classification is based on the possible radiation exposure to workers or the public. The radioactive properties are an inherent feature of the material and cannot be changed without

From a global perspective, zircon is generally not found in high concentrations other than in placer and dune deposits where it has been deposited along with other heavy minerals such as ilmenite, rutile, and monazite. Such deposits have been sorted and concentrated over geological time by the action of tides, waves, and wind to form concentrated deposits of heavy minerals along old coastlines and in river beds and deltas. Consequently, zircon is mostly found in association with the principal titanium minerals ilmenite and rutile. These secondary concentrations in placer deposits provide the commercial sources of zircon.

All geological materials contain natural radioactivity, although the term NORM (naturally occurring radioactive material) is mostly used for minerals and other materials with above-average uranium and thorium concentrations. Importantly, the radioactive nature of zircon has not changed, but the way in which radioactivity is viewed by regulators has, affecting the zircon industry throughout the value chain.

The Zircon Industry Association (ZIA) has 23 members spanning a good part of the value chain and representing some $80 \%$ of the

\begin{tabular}{|l|l|}
\hline \multicolumn{2}{|l|}{$\begin{array}{l}\text { Table I } \\
\text { Producer members of the Zircon }\end{array}$} \\
\hline Industry Association \\
\hline Member & Country \\
\hline $\begin{array}{l}\text { Iluka Resources Ltd } \\
\text { Kenmare Moma Processing } \\
\text { (Mauritius) Ltd }\end{array}$ & Australia \\
\hline Rio Tinto Iron \& Titanium Ltd. & United Kingdom \\
\hline Sibelco Australia Limited & Australia \\
\hline Tronox Mineral Sands (Pty) Ltd. & South Africa \\
\hline TiZir Limited & United Kingdom \\
\hline Base Resources Limited & Australia \\
\hline
\end{tabular}

* Zircon Industry Association (ZIA)

(C) The Southern African Institute of Mining and was first presented at the Heavy Minerals Conference 'Expanding the Horizon', 16-17 August 2016, Sun City, South Africa. Metallurgy, 2017. ISSN 2225-6253. This paper 


\section{Naturally occurring radioactive materials and the regulatory challenges}

altering the material itself. The radiation exposure that can result from the material, however, varies according to the handling procedures.

The radioactivity of a material is measured in becquerels per gram $(\mathrm{Bq} / \mathrm{g})$, where one becquerel is equal to 1 count (disintegration) per second. NORMs contain radionuclides of the uranium and thorium decay series and a radioactive potassium isotope. The uranium decay series has 14 members, starting with $\mathrm{U}^{238}$ and ending with $\mathrm{Pb}^{206}$, while the thorium series has 10 members, starting with Th232 and ending with $\mathrm{Pb}^{208}$ (Figure 1).

If the decay series is not disturbed, each member will have the same activity level; this is known as secular equilibrium. Many NORMs show secular equilibrium due to their age, and in order to classify a material, the state of equilibrium needs to be known.

The activity levels in zircon vary depending on the source, but are generally in the ranges shown in Table II.

Most zirconia $\left(\mathrm{ZrO}_{2}\right)$ is manufactured from zircon due to the scarcity of natural zirconia. The radioactivity of manufactured zirconia depends on the activity of the source zircon and the production process used. Thermal zirconia contains higher levels of radionuclides than the parent zircon, whereas chemically-produced zirconia may contain very low levels of radionuclides.

\section{Regulation of NORMs}

In terms of legislation applied to materials, the activity level where regulatory attention can be expected varies between countries, but a threshold value of $1 \mathrm{~Bq} / \mathrm{g}$ is generally used internationally (International Atomic Energy Agency, 2004). Individual countries may apply stricter limits than these international standards, and if a material contains $>1 \mathrm{~Bq} / \mathrm{g}$ it is classified as radioactive.

Zircon and zirconia containing above $1 \mathrm{~Bq} / \mathrm{g}$ are subject to regulatory attention in all jurisdictions. Whether regulations are applied to the handling of these materials depends on the country in question; however, from the focus that NORMs have received from both the International Commission on Radiological Protection (ICRP) and the
International Atomic Energy Agency (IAEA) it should be assumed that possession, handling, and use of zircon and zirconia will receive some level of regulatory attention in most countries. This attention may vary from simple 'notification' through 'registration' to the highest level - 'licensing'.

\section{Regulation of radiation exposure}

The exposure of workers to radiation is closely regulated in all countries and the limits applied in most cases follow the ICRP and IAEA recommendations. The current internationally-agreed exposure limit is 20 millisieverts (mSv) per year for a 'radiation worker'. Exposure in a single year may exceed this value provided that the exposure over a 5-year period does not exceed $100 \mathrm{mSv}$, (i.e. an average of 20 $\mathrm{mSv} / \mathrm{a})$.

Regulation also requires that if a person's exposure exceeds $1 \mathrm{mSv} / \mathrm{a}$ that person is considered as occupationally exposed and is classed as a radiation worker. If the operation has areas where exposure can exceed $1 \mathrm{mSv} / \mathrm{a}$, these areas are classified as supervised areas where a specific set of monitoring requirements is mandatory. If the exposure levels exceed $6 \mathrm{mSv} / \mathrm{a}$, the areas where this occurs are classed as controlled areas and more stringent forms of monitoring and control are required.

Radiation exposure of the public due to a zircon/zirconia handling operation is also regulated, with members of the public being limited to an exposure of $1 \mathrm{mSv} / \mathrm{a}$ from all

Table II

Typical activity ranges of radionuclides in natural raw materials

\begin{tabular}{|l|c|}
\hline Nuclide & Activity range $\mathbf{( B q} / \mathbf{g})$ \\
\hline Uranium-238 in zircon & $2-4$ \\
Thorium-232 in zircon & $0.5-1.0$ \\
Potassium-40 in zircon & Approx. 0.002 \\
Uranium-238 in natural zirconia & $3-13$ \\
Thorium-232 in natural zirconia & $0.1-26$ \\
\hline
\end{tabular}

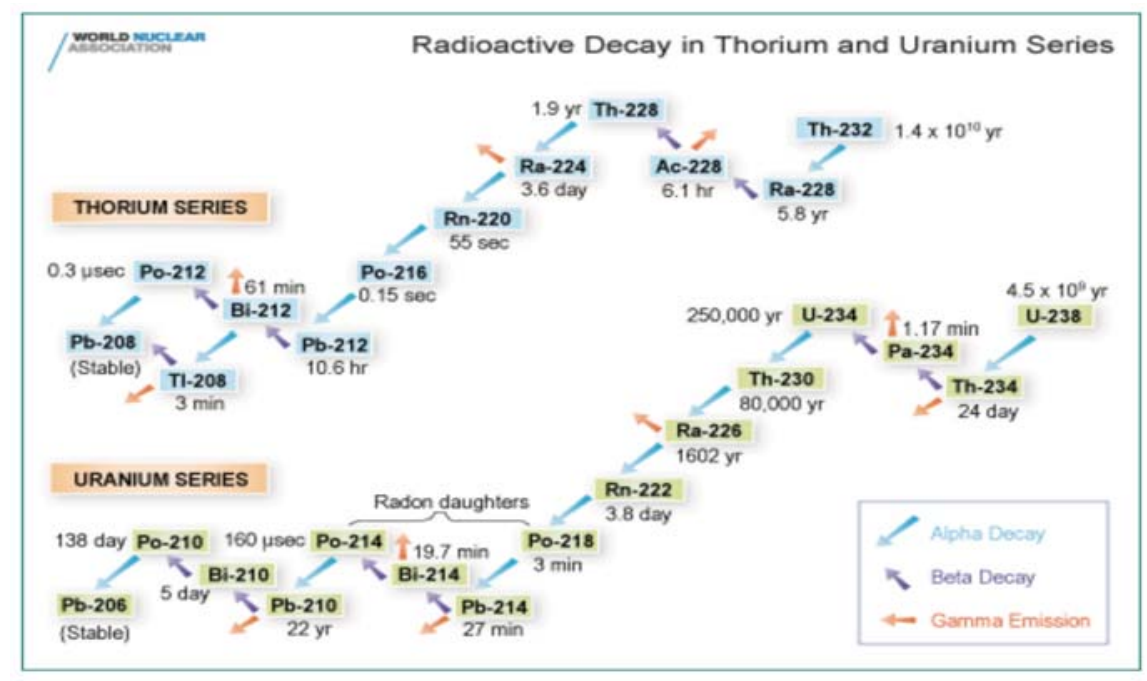

Figure 1-Radioactive decay in the Th and U series 


\section{Naturally occurring radioactive materials and the regulatory challenges}

sources, with constraints being applied for a single source. These single-source constraints are typically set at 0.3 $\mathrm{mSv} / \mathrm{a}$. For example, when zircon/zirconia is transported the exposure of the public from any spillages must be kept below $0.3 \mathrm{mSv} / \mathrm{a}$. Corrective action would be required if this limit is exceeded.

\section{Regulation of NORMs in the EU}

EU Member States are required to comply with the latest version of the Basic Safety Standards - "Council Directive, $2013 / 59 /$ EURATOM' of 2013, by 6 February 2018. For the first time, zircon is specifically referenced in the annexes to this update; namely:

\section{'Annex VI: List of industrial sectors involving naturally-occurring radioactive material as referred to in Article 23 ... When applying Article 23 the following list of industrial sectors involving naturally-occurring radioactive material, including research and relevant secondary processes, shall be taken into account: - Zircon and zirconium industry'.}

While the requirement of the 2013 version should be comfortably met by zircon operators in the EU, the fact that zircon is noted in the Annex could lead to greater examination from local authorities. In preparation for this, those operating in the EU should:

> Recognize that their operations will be subject to the scrutiny of the local regulator and prepare for an inspection

> Inform their regulators that they are processing 'radioactive materials' and conduct radiation risk assessments to ascertain the potential or actual exposure situation.

> Establish the levels in terms of $U$ and Th activity of wastes and be prepared for negotiations with regulators

- Ensure that they have adequate dose data to support the claim that the impact on the public from their operation is less than $0.3 \mathrm{mSv} / \mathrm{a}$.

The ZIA is maintaining a watching brief over the development of these regulations throughout the EU with the aim of forewarning members about any impending differences between Member States.

\section{EU-REACH}

The REACH (Registration, Evaluation and Authorisation of Chemicals) Regulation entered into force on 1 June 2007 with the aim of streamlining and improving the former legislative framework for chemicals management in the EU. REACH also created the European Chemicals Agency (ECHA) in Helsinki, which has a central coordination and implementation role in the overall process by managing the registration, evaluation, and authorization steps to ensure consistency across the EU.

Two basis concepts are attributable to REACH: the shift of the burden-of-proof of safe use from authorities to industry, and the stated 'No data no market' (REACH Regulation, Article 5), whereby substances shall not be manufactured in or placed on the EU market unless they have been registered in accordance with the relevant provisions of the Regulation.
To date, some 45000 registrations covering 9500 unique substances have been received by ECHA. Table III shows the top five registrations by country, and Table IV, by substance.

\section{EU REACH and zircon}

Although the term 'chemical' is not generally associated with metals, ores, and minerals, it is clear that reference to chemical substance, or substance, does include all organic, inorganic, and natural substances found in the periodic table along with all combinations, or mixtures, of these. In fact, substance is defined in REACH Article 3(1) as:

... a chemical element and its compounds in the natural state or obtained by any manufacturing process, including any additive necessary to preserve its stability and any impurity deriving from the process used, but excluding any solvent which may be separated without affecting the stability of the substance or changing its composition'.

Importantly, there are some notable exemptions from registration obligations as detailed in Annexes IV and V of the Regulation. For example, substances for $R \& D$ purposes, substances used in the interests of defence, and those substances managed by other legislation, such as food additives, radioactive substances, or medical applications are exempt for a period of time.

For the minerals industry, exempted substances in Annex $\mathrm{V}(7)$ include: 'The following substances which occur in nature, if they are not chemically modified. Minerals, ores, ore concentrates, cement clinker, natural gas, liquefied petroleum gas, natural gas condensate, process gases and components thereof, crude oil, coal, coke.'

Zircon, along with other minerals, is therefore exempted from $\mathrm{REACH}$ registration obligations.

Table III

Overview of top five countries to 13 May 2016 (ECHA)

\begin{tabular}{|l|c|}
\hline Country & Number of registrations \\
\hline Germany & 11677 \\
United Kingdom & 5488 \\
France & 4008 \\
Netherlands & 3932 \\
Italy & 511 \\
\hline
\end{tabular}

Table IV

Overview of top five substances to 13 May 2016 (ECHA)

\begin{tabular}{|l|c|}
\hline Substance & Number of registrations \\
\hline Calcium dihydroxide & 457 \\
Ethanol & 459 \\
Ethylene oxide & 398 \\
Iron & 391 \\
Calcium sulphate & 300 \\
\hline
\end{tabular}




\section{Naturally occurring radioactive materials and the regulatory challenges}

Chemical derivatives of zircon are, however, subject to $\mathrm{REACH}$ registration at $>1 \mathrm{t} / \mathrm{a}$ per legal entity registrant. Analyses of some zirconia-based substances are given in Table V.

Parallel to the REACH registration process was the introduction of the Classification, Labelling, and Packaging (CLP) regulation-the EU's equivalent to the Globally Harmonised System of Classification and Labelling (or GHS) - where all substances, including those exempt from $\mathrm{REACH}$ registration obligations, are classified through a process of notification. It is here that we see zircon and entries for zirconium orthosilicate and zirconium silicate. These notifications include a number of different classifications for the same substance: e.g. zircon is classified variously by different producers as:

> Unclassified

Skin irritation 2

- Eye irritation 2

[H315-causes skin irritation] [H319-causes serious eye irritation]

> Carcinogen $1 \mathrm{~A}$ [H350-may cause cancer].

It is not unusual for there to be different classifications for the same substance: some may be default classifications; others may be precautionary. However, these classifications are in the public domain and must be addressed to reflect an industry-agreed, single classification.

\section{REACH around the world}

While REACH pertains to the EU, regulatory derivatives are developing in other jurisdictions as industrialized nations grapple with the complexities of chemicals management. A strong motivation for this is the UN Strategic Approach to International Chemicals Management (SAICM); a policy framework to foster the sound management of chemicals around the world. SAICM aims to achieve the sound management of chemicals throughout their life cycle so that, by 2020 , chemicals will be produced and used in ways that minimize significant adverse impacts on human health and the environment. This '2020 goal' was adopted by the World Summit on Sustainable Development in 2002 as part of the Johannesburg Plan of Implementation.

In order to meet this goal, many regions have been encouraged by the reported successes of EU-REACH to look at implementation of a similar legislative framework, some with an almost copy/paste approach, from China to South Korea and Turkey, each of which have implemented, or are in the process of introducing, REACH-like laws. While many of the legislative terms may be familiar to those involved with EU-REACH (e.g. 'downstream user', 'only representative', 'exposure scenario'), care should be taken to understand the detail of these derivatives as there are some important differences, e.g. the requirement for annual tonnage reporting in Korea's K-REACH.

Other industrialized countries that have not fully implemented regulatory change are starting with the cataloguing of all existing chemicals on their market (e.g. Brazil, Taiwan, and India). Care has to be taken to monitor each list as it is published, as these often then lead to the classification and prioritization of substances for future registration.

\section{Ocean shipping and the International Maritime Organization}

While regulatory developments progress on land, the updating of various ocean shipping codes by the International Maritime Organization (IMO) also has an impact on international trade. Based in London, the IMO is a specialized agency of the UN that is responsible for measures to improve the safety and security of international shipping and to prevent pollution from ships. Its stated objective is 'safe, secure and efficient shipping on clean oceans'.

IMO's governing body is the Assembly, which is made up of all 171 Member States, and a Council of 40 Member States acts as its governing body between Assembly sessions. In practice, the main technical work is carried out by five committees-Maritime Safety, Marine Environment Protection, Legal, Technical Co-operation, and Facilitationsupported by a number of sub-committees. Outputs from these committees include several codes that lay out the legal framework for the shipping of goods in bulk and in containers.

Two codes can have an impact on the shipping of zircon and other minerals; namely the International Maritime Solid Bulk Cargoes (IMSBC) Code and the International Convention for the Prevention of Pollution from Ships (MARPOL).

The aim of the IMSBC Code is to enable the safe stowage and shipment of solid bulk cargoes by providing information on the dangers and precautions associated with the shipment of certain types of cargo in bulk. The IMSBC Code categorizes cargoes into three groups:

Group A: Cargoes that may liquefy

Group B: Cargoes that pose a chemical hazard that could give rise to a dangerous situation on a ship

Group C: Other cargoes that can still be hazardous (e.g. very dense cargoes that can damage a vessel's structure due to poor loading procedures).

Importantly, these characteristics refer to the bulk cargo properties rather than a hazard from the material itself. For

Table $V$

The top five REACH-registered Zr-based substances

\begin{tabular}{|l|c|c|c|}
\hline Name & Chemical Abstracts Service (CAS) number & No. of registrants \\
\hline Zirconium & $7440-67-7$ & 4 & $1000-10000$ \\
Zirconium dioxide & $1314-23-4$ & 37 & $10000-100000$ \\
Zirconium dioxide Y-doped & $64417-98-7$ & 3 & $100-1000$ \\
Calcium zirconium oxide & $11129-15-0$ & $1000-10000$ \\
Zirconium sulphate & $14644-61-2$ & $1000-10000$ \\
\hline
\end{tabular}




\section{Naturally occurring radioactive materials and the regulatory challenges}

example, liquefaction (where a bulk cargo becomes fluid) is a property displayed only in bulk form. Cargoes prone to liquefaction contain a certain quantity of moisture and small particles, although they may look relatively dry and granular when loaded. Liquefaction can lead to vessel instability and even to capsize and total loss of the ship, and can occur even when cargoes are cohesive and trimmed level.

Zircon sand is currently cargo Group C, whereas other minerals are assigned different codes-for example ilmenite sand is Group A or C.

Importantly, there is an ongoing review to classify ilmenite sand as Group A due to its liquefaction potential. In addition, the reference to 'sand' in the cargo description erroneously introduces an association with the health effects due to the inhalation of silica dust. Efforts are underway to inform and educate the relevant IMO technical committees that such reference to sand in mineral cargo descriptions relates to the physical form of the cargo rather than the presence of silica sand.

Transport of materials by ocean freight also has to comply with the requirements of the International Maritime Dangerous Goods Code (IMDG). This code is controlled by the IMO, but fortunately the IMO has aligned its standards with those of the IAEA so the same limits apply. By not exceeding the $10 \mathrm{~Bq} / \mathrm{g}$ limit, zircon and zirconia may be shipped internationally without the requirement to comply with the IAEA transport regulations or the IMDG Code. Being not classified as a radioactive material in the IMDG Code means the concentrates avoid classification as 'Hazard Class 7 radioactive substances.' Shipping companies are reluctant to handle Class 7 materials, so this is a distinct advantage for the export of this material.

The status of radiation-based regulations in the destination port also needs to be confirmed. Although the country may subscribe to the IAEA standards, there have been situations where port officials apply different standards to those defined internationally. This inconsistency may also vary between ports in the same country. The radioactivity of zircon/zirconia does not require it to be governed by the IAEA transport regulations, and storage as part of transportation is also not mandated by the international standards. However, the detection of a radioactive signature from the material may trigger some reaction from port officials, which could delay the movement of cargo.

\section{Conclusions}

> Although NORM and radiation developments are at the end of a cycle, zircon operations should aim to proactively manage regulatory developments $(e . g$. meeting with relevant authorities and targeted advocacy)

> For those areas of potential higher worker exposure to NORM dust, such as dry milling of zircon, appropriate risk assessments should be undertaken and kept updated

> Regulations are harmonizing globally (land and sea), becoming more stringent and shifting the burden of proof from regulators to industry. It is vital to be aware of developments globally and plan/act accordingly.

The Zircon Industry Association (ZIA) is working to support its members' knowledge of and compliance with major regulations impacting the full supply chain.

\section{Acknowledgements}

The author would like to express his thanks to colleagues at ZIA, and to J.H. Selby for his various reports to the ZIA.

\section{References}

International Atomic Energy Agency. 2004. Application of the Concepts of Exclusion, Exemption and Clearance. IAEA Safety Standards Series, Safety Guide No. RS-G-1.7. Vienna.

Zircon Industry Association. www.zircon-association.org 